University of Wollongong

Research Online

Faculty of Engineering and Information

Faculty of Engineering and Information

Sciences - Papers: Part B

Sciences

2019

Work Pattern of Neurology Nurses in a Chinese Hospital: a Time and

Motion Study

Ping Yu

University of Wollongong, ping@uow.edu.au

Liying Song

Zhejiang University

Siyu Qian

University of Wollongong, sqian@uow.edu.au

X Yao

Huzhou Central Hospital

Jue Huang

Zhejiang University

See next page for additional authors

Follow this and additional works at: https://ro.uow.edu.au/eispapers1

Part of the Engineering Commons, and the Science and Technology Studies Commons

Research Online is the open access institutional repository for the University of Wollongong. For further information contact the UOW Library: research-pubs@uow.edu.au 


\title{
Work Pattern of Neurology Nurses in a Chinese Hospital: a Time and Motion Study
}

\begin{abstract}
Aim: To investigate nursing work patterns in a neurology department in a Chinese hospital. Background: Knowledge of nursing work patterns is important for nursing management and work design, and for the evaluation of organizational process change associated with the introduction of an innovation.

Methods: A time-and-motion method was used to observe 14 registered nurses' (RNs') work patterns in a neurology department in a Chinese hospital. Results: There were $147 \mathrm{hr}$ of observation. Overall, the most time-consuming activities were verbal communication (28.5\%) and documentation (28.3\%), followed by indirect care $(14.6 \%)$ and direct care (14\%). Compared to support RNs, charge RNs spent $20 \%$ more time on documentation and $11 \%$ more time on verbal communication. Two-thirds of the observed activities had a duration of less than $40 \mathrm{~s}$.

Conclusions: Communication, in verbal and written forms, consumed more than half of the nursing time. Conversely, nurses only spent about a quarter of their worktime on preparation for care provision and direct care provision. This reflects the significant role and resource-consuming nature of communication to provide safe and quality care.

Implications for Nursing Management: Communication methods need to be enhanced to improve nursing productivity. This may be achieved through the introduction of more effective nursing documentation methods.

Disciplines

Engineering | Science and Technology Studies

\section{Publication Details}

Yu, P., Song, L., Qian, S., Yao, X., Huang, J., Min, L., Lu, X., Duan, H. \& Deng, N. (2019). Work Pattern of Neurology Nurses in a Chinese Hospital: a Time and Motion Study. Journal of Nursing Management, 27 (2), 320-329.
\end{abstract}

\section{Authors}

Ping Yu, Liying Song, Siyu Qian, X Yao, Jue Huang, Lingtong Min, Xudong Lu, Huilong Duan, and Ning Deng 
1 Work Pattern of Neurology Nurses in a Chinese Hospital: a Time and Motion Study

\section{Abstract}

3 Aim To investigate nursing work pattern in a neurology department in a Chinese hospital.

4 Background Knowledge of nursing work pattern is important for nursing management and

5 work design, and evaluation of organizational process change associated with the

6 introduction of an innovation.

7 Methods Time and motion method was used to observe 14 registered nurses' (RNs) work

8 pattern in a neurology department in a Chinese hospital.

9 Results 147 hours of observation were conducted. Overall, the most time-consuming activity was verbal communication (28.5\%) and documentation (28.3\%) followed by indirect care

11 (14.6\%) and direct care (14\%). Compared to Support RN, Charge RN spent 20\% more time on documentation and 11\% more time on verbal communication. Two thirds of the observed activities had duration less than 40 seconds.

14 Conclusions Communication, in verbal and written format, consumed more than half of nursing time. Conversely nurses only spent about a quarter of their worktime on preparation for and direct care provision. This reflects the significant role and resource-consuming nature

17 of communication to provide safe and quality care.

Implications for Nursing Management Communication methods need to be improved so as to improve nursing productivity. This may be achieved through the introduction of more 
1 effective nursing documentation method.

2 Key words: nurse, nursing work, activity, hospital, neurology, time and motion, observation 


\section{Introduction}

2 Knowledge of nursing work pattern is important for nursing work design, resource allocation,

3 staff performance appraisal (Qian, Yu, Zhang, Hailey, Davy \& Nelson, 2012), identification

4 of areas needing improvement (Cornell, Herrin-Griffith, Keim, Petschonek, Sanders, D'Mello,

5 Golden \& Shepherd, 2010), and evaluation of organizational process change associated with

6 the introduction of an innovation (Guo, Watts \& Wharrad, 2015). Nursing work pattern can

7 be identified from the daily activities of a representative sample of nurses in a nursing unit,

8 such as the amount of time, duration and frequency of an activity, as well as the sequence of

9 activities. The amount of time nurses spend with patients is associated with quality and safety

10 of care (Cho, Lee, Kim, Kim, Lee, Park \& Sung, 2016) and patient satisfaction (Hockenberry

11 \& Becker, 2016). It also links to the nurses' job satisfaction, which is critical for nurse

12 retention (Hayes, Bonner \& Pryor, 2010).

13 The work pattern measurement in healthcare settings is usually conducted with three techniques: self-reporting daily logs, observation with work sampling method and time and motion observational study. Self-reporting daily logs ask individuals to record their activities at frequent intervals. Although this method can capture the tasks being performed, the accuracy of reporting suffers from subjectivity of perceptions and recall error, let alone lapse in rush hours (Ampt, Westbrook, Creswick \& Mallock, 2007).

Work sampling technique has been developed to capture workers' activities. This method measures the activity of a group of individuals (Pelletier \& Duffield, 2003). Its advantage is to allow a single observer to record all the activities conducted by all the study subjects 
1 during a period of time. As it is well-planned and objectively conducted by a trained

2 researcher, it is usually more accurate than self-reporting logs. However, in this method the

3 time expenditure of an activity was estimated instead of counting the actual time. This may

4 not be accurate. It may also cause loss of certain useful information such as the interaction

5 among nurses or between nurses and patients.

6 In a time and motion study, an observer measures and records every activity performed by a

7 healthcare worker and the exact amount of time the person spends on the activity (Qian et al.,

8 2012). Thus it is able to provide an accurate recording of the amount of time, duration and

9 frequency of an activity, as well as the sequence of activities.

10 Although nursing time studies can be dated back to 1950s (Abdellah \& Levine, 1954) and

11 have been conducted in many countries over the decades (Williamson Jr \& Johnston, 1988,

12 Urden \& Roode, 1997, Williams, Harris \& Turner-Stokes, 2009, Antinaho, Kivinen, Turunen

13 \& Partanen, 2014), to our knowledge, there has been no report on nursing work pattern and

14 time expenditure in hospitals in mainland China. This knowledge is vital for enriching and

15 advancing the field of international nursing management and leadership. Therefore, this study

16 aimed to empirically investigate the work patterns of nurses in a Chinese hospital using the

17 time and motion observation method.

\section{Methods}

Study setting

According to the Management Standards of Hospital Classification used by the Ministry of 
1 Health in China, hospitals are classified into three grades according to its number of beds.

2 Hospitals with no more than 100 beds are in Grade 1, those with 100 to 500 beds are in Grade

3 2, and those with more than 500 beds are in Grade 3. In each grade, there are three classes; A,

4 B and C. The criterion for a Class 3A hospital is achieving 900 out of 1000 points in hospital

5 accreditation. The main aspects of accreditation assessment include systems and management,

6 medical service quality and safety, and the level of technology usage and efficiency.

7 There were, in total, 776 Class 3A hospitals in China in 2015. As hospitals in this grade

8 provide the highest quality of services, the nursing services in these hospitals are the model

9 services for the hospitals in lower grades in China. Therefore, to maximize the value of the

10 study to provide insight and exemplary outcomes for hospitals in the same and lower grades

11 to learn and improve their management, we chose a Class 3A hospital to conduct this study.

12 The Huzhou General Hospital is a teaching hospital affiliated with Zhejiang University. It is located in Huzhou, Zhejiang Province, China. It had 1,200 beds in 34 wards and an intensive care unit. The observation was conducted in the Neurology Department because this department was selected as the test site to implement a PDA-enabled electronic medication management system in the hospital. To establish a baseline for the evaluation of the impact of the innovation, the baseline data need to be collected.

The department had 40 beds, 36 were occupied during the study period. The top five common diseases treated in the unit were cerebrovascular disease, epilepsy, Parkinson's disease, primary headache and vestibular peripheral vertigo. Except two patients who needed to be observed every 15 to 30 minutes, the rest 34 patients were stable, could conduct light 
1 activities in bed or indoor. They required nursing observation every one to two hours.

$2 \quad$ Staffing

3 The Neurology Department was staffed by 16 registered nurses (RNs), each had at least

4 three-year university education. On a working day, a nurse might be in charge (Charge RN)

5 or in support (Support RN) role. The difference between these two types of RNs was a

6 Charge RN had clear caring responsibility for patients allocated to her; whereas the Support

7 RN was "floating" around to provide helping hands to the Charge $\mathrm{RN}$ when the later was

8 fully occupied to respond to further duty.

9 In a day shift from 8 am to 8 pm, four Charge RNs and three Support RNs provided nursing care to 36 patients. All Charge RNs worked from 8 am to 5 pm. One Support RN worked from 7:45 am to 3:45 pm, another worked from $12 \mathrm{pm}$ to $8 \mathrm{pm}$, and the third worked from 8 am to $12 \mathrm{pm}$ and then from $5 \mathrm{pm}$ to $8 \mathrm{pm}$. Therefore, the nurse-to-patient ratio was 1:6 from 8 am to 5 pm, and reduced to $1: 18$ after $5 \mathrm{pm}$.

\section{Ethical considerations}

Ethical approval was granted by the ethics committee of the participant hospital based on the written approval given by the university and the approval by the Head Nurse in the hospital. The observer was introduced to the nursing staff by the Director of Nursing (DON) in the Neurology Department. To ensure that the nurses' participation in the study was completely voluntary, the researchers informed the nurses that the study was independent from hospital operation and participation 
1 in it was completely voluntary. Nurses could choose to refuse to participate or withdraw their

2 data from the study at any time and their refusal or withdrawal of data would not affect any

3 relationship that they had with the unit, the hospital or the university. It was also made

4 explicit that the research data collected from them would be stored securely in the password

5 protected computers of the researchers and were only accessible by the researchers. On each

6 observation day, the observer re-iterated the study purpose and procedure, and the voluntary

7 nature of participation. Only after explicit written consent was acquired from the person, was

8 observation of the person's activities permitted to begin.

$9 \quad$ Classification of nursing activities

10 A four-step process was followed for the development of the classification system of nursing activities: 1) identification of nursing activities and their classifications from the literature, 2) field observation to identify nursing activities specific to the study setting, 3) validation of nursing activities by unit nurses and 4) field testing the validity of the classification system.

In the first phase, hospital nursing activities, their definitions and classifications were identified from the literature (Capuano, Bokovoy, Halkins \& Hitchings, 2004, Chaboyer, Wallis, Duffield, Courtney, Seaton, Holzhauser, Schluter \& Bost, 2008, Hendrich, Chow, Skierczynski \& Lu, 2008, Lee, Mills \& Lu, 2008, Williams et al., 2009, Abbey, Chaboyer \& Mitchell, 2012, Antinaho et al., 2014).

19 In the second phase, the observer observed two Charge RNs from 8 am to 5 pm on two separate days. She recorded all activities conducted by each RN in the whole shift. Brief communication with the RNs was conducted to clarify the nature of an activity whenever it 
was needed.

2 In the third phase, nursing activities identified from the literature and those directly observed

3 in the field were synthesized. The DON and two nurses reviewed, discussed and revised the

4 list. This resulted in 67 activities grouped into eight categories: direct care, indirect care,

5 infection control, documentation, staff break, transit, verbal communication and other

6 activities (Table 1). The definitions of direct care and indirect care were adopted from the

7 previous studies (Pelletier et al., 2003, Williams et al., 2009). Direct care is "nursing care

8 activities performed in the presence of the patient and/or family". Indirect care is "nursing

9 care activities performed away from the patient, but on a specific patient's behalf”. Three

10 important nursing activities - verbal communication, documentation and infection control -

11 were initially included in the categories of direct care and indirect care. In order to acquire

12 enough granularity, we separated these three activities into independent categories of their

13 own, differentiating them from those of direct care and indirect care.

14 In the last phase, the classification system was validated in a two-day observation with a

15 participant nurse who had extensive experience in nursing practice. The observer and the

16 nurse independently observed the same activities. Then the two discussed the similarities and

17 differences of their records. The results suggested that the classification system was valid in

18 representing the nursing activities in the unit. 
1

Study participants

2 Fourteen out of $16(86.5 \%$ of $)$ nurses working in the unit were observed. There were nine

3 Charge RNs and five Support RNs. Due to the availability of nurses at duty during the

4 observational period, two Charge RNs and one Support RN were observed twice. The rest 11

5 nurses were observed once each. Therefore, the nursing activities in the unit were adequately

6 captured.

$7 \quad$ Sample size

8 The number of participants observed was confined by the actual number of nurses working in

9 the study unit and the availability of the observer. The unit of analysis, however, was the activity, rather than individual nurses, so the sample size was determined as the total number

11 of activities to be recorded. Using the statistical power calculation formula suggested by

12 Sittig (Sittig, 1993) and data collected from the pilot observation, it was determined that the total number of activities needed to be observed was 1,824 and 1,411 for Charge RN and

Support RN, respectively. In the formal data collection, 5,368 and 2,549 activities were recorded for the two types of nurses, respectively, larger than the estimated sample size.

\section{Field data collection}

Data collection was carried out over a period of 17 days in 2014. The convenience sampling approach was used to select one nurse to observe on each day. An Excel spreadsheet with a pre-entered classification system of activities on a handheld tablet computer was used to record nursing activities. To enable fast recording, only the end time was recorded for an 
1 observed activity because the end time of the current activity was the start time of the next

2 one. When a nurse spoke and performed another activity concurrently, the observer recorded

3 both the start and the end time of this verbal communication activity. Other information

4 recorded included date and period of observation and the job role of the nurse.

$5 \quad$ Data analysis

6 The data was entered into an Excel spreadsheet and imported to SPSS 19.0 (SPSS Inc.,

7 Chicago, IL, USA) for analysis of activity time, frequency and duration. A z test was used to 8 compare the percentage of time spent on each category of activities between the two types of 9 nurses. A statistically significant difference was assumed when the p value was less than 0.05.

\section{Results}

11 All of the designated 67 activities were observed. Fourteen nurses were observed for a period 12 of 17 days, a total of 147.2 hours of observation. 7,917 activities were recorded, 5,368 for 13 Charge RN and 2,549 for Support RN. Nursing work pattern in the Neurology Department in 14 Huzhou General Hospital was presented below in terms of nursing time on different categories of activities, activity frequency and duration, and sequence of activities.

17 Figure 1 shows the nursing time spent on each category of activities. The percentage did not necessarily add up to $100 \%$ because verbal communication may occur either by itself or simultaneously with another activity; thus overlapping with that activity. 
1 Nurses spent 28.5\% (95\% confidence interval [CI]: 23.9-33\%) of their time on verbal

2 communication, with $8.8 \%$ of this communication time concurrently spent on doing another

3 activity. The second most time-consuming activity was documentation (28.3\%, 95\% CI:

4 21.9-34.8\%). This was followed by indirect care (14.6\%, 95\% CI: 8.9-20.2\%), direct care

5 (14.0\%, 95\% CI: 11.8-16.1\%), staff break (8.8\%, 95\% CI: 5.2-12.3\%), transit (8.2\%, 95\% CI:

6 6.5-9.9\%), infection control (3.6\%, 95\% CI: 2.7-4.5\%) and other activities (2.8\%, 95\% CI:

$7 \quad 1.1-4.5 \%)$.

8 Insert Figure 1 about here

9 The most time-consuming direct care activity was 'intravenous infusion' at about 28 minutes

10 per eight-hour shift. This was followed by 'changing or withdrawing intravenous medication'

11 at about 10 minutes over an eight-hour shift. The most time-consuming indirect care activity was ‘preparing medications according to prescriptions’ at about 20 minutes.

Figure 2 presents the time, frequency and duration by activity category for each type of nurse.

Charge RN spent significantly less time than Support RN on 'indirect care’ (8.2\% vs. 26.2\%, $\mathrm{p}<0.0001)$, 'staff break' (6.9\% vs.12.3\%, $\mathrm{p}<0.01)$, and 'transit' (6.5\% vs. $11.3 \%, \mathrm{p}<0.0001)$.

In a sharp contrast with Support RN, Charge RN spent more time on 'documentation’ (35.5\% vs. $15.3 \%, \mathrm{p}<0.0001$ ) and 'verbal communication' (32.5\% vs. $21.1 \%, \mathrm{p}<0.001)$.

No statistically significant difference between the two types of nurses was found in their time spent on 'direct care', 'infection control' and 'others'; and these activities took approximately 
$20.4 \%$ of their working time.

2

3

4

5

6 Activity duration was short and varied dramatically (Figure 2). For Charge RN, the average

7 durations of direct care, infection control and documentation were longer than one minute,

8 whereas the average duration of indirect care and verbal communication were less than one

9 minute. There was a similar pattern for the Support RN, except for indirect care which has a

10 longer duration than that of the Charge RN.

11 Figure 3 shows the distribution of durations of activities. Of the 7,917 activities recorded,

$1222.5 \%$ were completed in less than 10 seconds, and 23.3\% took between 10 and 19 seconds.

13 Overall, about two-thirds of the observed activities in the ward had a very short

14 duration-less than 40 seconds.

15 Insert Figure 3 about here

\section{Sequence of activities}

17 Figure 4 depicts the pattern of nursing activity sequence. The eight activity categories are presented as nodes. A directed edge between two nodes represents a switch from one activity to another. The thickness of an edge represents the level of frequency of the switch. The 
1 thicker the edge, the more frequent a switch occurred.

2 Insert Figure 4 about here

3 On average, 61.3 switches between two consecutive activities were observed in an hour, one

4 per minute. The directions of the most frequently observed switches were within or between

5 verbal communication, direct care, transit and documentation by Charge RN. As to Support

$6 \mathrm{RN}$, the most frequent switches were within or between indirect care, transit and direct care.

\section{Discussion}

8 For the first time, this study investigated the nursing work pattern in a Neurology Department

9 in a Chinese tertiary hospital. This included the actual nursing time spent on an activity, the

10 frequencies, durations and sequence of activities over a twelve-hour shift.

11 The nursing activity classification system developed in our study includes 67 distinctive 12 nursing activities. This high level of granularity facilitates accurate identification and 13 recording of nursing activities in field observations. It is useful for nursing work redesign, 14 hospital unit organization, and evaluation of change in nursing work following the 15 introduction of new innovations e.g. mobile nursing documentation system into nursing work.

16 Compare to other classifications of hospital RNs' activities (see Table 2), our classification 17 distinguishes communication, transit and infection control (e.g. washing hands) from the others so as to highlight the resource of nursing time required for these activities. 
1 Documentation accounts for $28 \%$ of nurses' time in this study, which is similar to $27.5 \%$

2 found from 767 nurses across 36 US hospitals (Hendrich et al., 2008) but higher than 16\%

3 and 13\% found in a Finnish hospital (Antinaho et al., 2014) and a US hospital (Capuano et al.

4 2004), respectively. This suggests that nursing workload in documentation may vary a lot in

5 different health systems in different countries. In addition to the difference in professional

6 practice, the other possible factors that contribute to the differences in documentation

7 workload may include documentation policy in a hospital, legal requirements for nursing

8 documentation in different countries and documentation tools used.

9 Support RN spent significantly more time on indirect care and transit than Charge RN, but

10 less time on documentation and verbal communication. These differences clearly show the

11 difference in the duties and responsibilities between the two nursing roles. Support RN

12 performed more indirect care activities as requested by Charge $\mathrm{RN}$, consequently transiting

13 more.

14 Compared to Support RN, Charge RN spent significantly less time on staff break but 20\% more time on documentation and $11 \%$ more on verbal communication. This may be because in order to fulfil the responsibility of patient care, the Charge RN had to take longer time,

17 sometimes overtime, to complete the verbal and written communication at the cost of reducing own break time.

19 It is interesting to note that both types of nurses spent the same amount of time on direct care

20 (14\%). This might be because that the two types of nurses always conducted direct care 21 activities together. 
1 Like the study which examined the work pattern of nurses in two medical-surgical units of a

2 US hospital (Cornell et al., 2010), we also found that sequence of nursing activities seemed to

3 be chaotic with frequent switches between activities. Cornell et al. (2010) found more than 40\%

4 of activities had a duration of less than 10 seconds, about twice of those (22.5\%) found in our

5 study. In fact, we found that $23.3 \%$ of nursing activities had a duration of 10 to 20 seconds.

6 Both studies expose the busy nature of hospital nursing care, which requires nurses to

7 constantly switch among activities fairly rapidly. This can be a source of nursing stress and

8 burnout.

\section{$9 \quad$ Limitations}

10 One of the limitations was the small number of nurses observed, limited by the total number

11 of nurses working in the department and the availability of the observer. The number of 12 participants observed, however, accounted for $87.5 \%(14 / 16)$ of all nurses working in the study setting, validly representing nursing activities in the study unit. Although patient disease severity can be a key factor to account for nursing management (Buffel du Vaure, Ravaud, Baron, Gilberg \& Boutron, 2016) and workload (Kraljic, Zuvic, Desa, Blagaic, Sotosek, Antoncic \& Likic, 2017), the conditions of most patients in the study unit were

17 similarly stable, thus it is not possible for us to identify the relationship between patients' disease severity and nursing work arrangement in this natural setting.

The benefit of using a single observer is to ensure consistency of activity recording but this can cause systematic errors in observation. This potential limitation was addressed by a pilot observation with a nurse to validate the observation, followed by a two-day observation 
conducted by two observers to test the intra-rater reliability, which was satisfactory.

2 We made an effort to minimise the Hawthorne effect, i.e. the influence of the observer on 3 nurses' behaviour (Westbrook \& Ampt, 2009). As found in the previous studies (Schnelle,

4 Ouslander \& Simmons, 2006, Ampt et al., 2007, Westbrook et al., 2009, Munyisia, Yu \&

5 Hailey, 2011), we noticed that in the busy hospital healthcare environment, the Hawthorne

6 effect caused by direct observation was not significant because the nurses had to concentrate

7 on nursing activities and quickly ignore the presence of the observer.

\section{Conclusion}

9 This study investigates the nursing work pattern and time expenditure in a neurology department in a Chinese hospital. Verbal communication, documentation, direct care and

11 indirect care consumed majority of nursing time. The short activity duration and frequent

12 switches between activities depict a busy nursing work in meeting the diverse demands of

13 patient care. Charge RN spent more time on documentation and verbal communication but

14 less time on indirect care and transit than the Support RN. Both categories of nurses spent the same amount of time on direct care.

\section{Implications for nursing management}

17 Although there were some studies investigating how nurses spent their time in hospital settings in some countries, little is known about the situation in Chinese hospitals. This case study contributes to knowledge about nursing work pattern and time expenditure in a neurology department in a Chinese hospital. 
The results indicate that for the optimal delivery of nursing care, verbal communication and documentation are equally important. Therefore, improving nurse's verbal communication and documentation skills is an important component for the improvement of quality of hospital nursing care.

Knowledge of nursing work pattern and time expenditure can help nursing managers to evaluate the impact of future improvement effort. It is vital for enriching and advancing the field of international nursing management and leadership.

\section{References}

Abbey, M., Chaboyer, W. \& Mitchell, M. (2012). Understanding the work of intensive care nurses: A time and motion study. Aust Crit Care, 25 (1), 13-22.

Abdellah, F.G. \& Levine, E. (1954). Work sampling applied to the study of nursing personnel. Nursing Research, 3 (1), 11-16.

Ampt, A., Westbrook, J., Creswick, N. \& Mallock, N. (2007). A comparison of self-reported and observational work sampling techniques for measuring time in nursing tasks. J Health Serv Res Policy, 12 (1), 18-24.

Antinaho, T., Kivinen, T., Turunen, H. \& Partanen, P. (2014). Nurses' working time use - how value adding it is? Journal of Nursing Management, 3 (10), 12258.

Blay, N., Duffield, C.M., Gallagher, R. \& Roche, M. (2014). Methodological integrative review of the work sampling technique used in nursing workload research. Journal of Advanced Nursing, 70 (11), 2434-2449.

Buffel du Vaure, C., Ravaud, P., Baron, G.B., C., Gilberg, S. \& Boutron, I. (2016). Potential workload in applying clinical practice guidelines for patients with chronic conditions and multimorbidity: A systematic analysis. BMJ Open, 6 (3), e010119.

Capuano, T., Bokovoy, J., Halkins, D. \& Hitchings, K. (2004). Work flow analysis: Eliminating non-value-added work. Journal of Nursing Administration, 34 (5), 246-256.

Chaboyer, W., Wallis, M., Duffield, C., Courtney, M., Seaton, P., Holzhauser, K., Schluter, J. \& Bost, N. (2008). A comparison of activities undertaken by enrolled and registered nurses on medical wards in australia: An observational study. International journal of nursing studies, 45 (9), 1274-1284.

Cho, E., Lee, N.-J., Kim, E.-Y., Kim, S., Lee, K., Park, K.-O. \& Sung, Y.H. (2016). Nurse staffing level and overtime associated with patient safety, quality of care, and care left undone in hospitals: A cross-sectional study. International Journal of Nursing Studies, 60, 263-271.

Cornell, P., Herrin-Griffith, D., Keim, C., Petschonek, S., Sanders, A.M., D'Mello, S., Golden, T.W. \& Shepherd, G. (2010). Transforming nursing workflow, part 1: The chaotic nature of nurse activities. J Nurs Adm 40 (9), 366-373.

Guo, P., Watts, K. \& Wharrad, H. (2015). An integrative review of the impact of mobile technologies used by healthcare professionals to support education and practice. Nursing Open. 
Hayes, B., Bonner, A. \& Pryor, J. (2010). Factors contributing to nurse job satisfaction in the acute hospital setting: A review of recent literature. Journal of Nursing Management, 18 (7), 804-814.

Hendrich, A., Chow, M.P., Skierczynski, B.A. \& Lu, Z. (2008). A 36-hospital time and motion study: How do medical-surgical nurses spend their time? The Permanente Journal, 12 (3), 25.

Hockenberry, J.M. \& Becker, E.R. (2016). How do hospital nurse staffing strategies affect patient satisfaction? ILR Review, 0019793916642760.

Kraljic, S., Zuvic, M., Desa, K., Blagaic, A., Sotosek, V., Antoncic, D. \& Likic, R. (2017). Evaluation of nurses' workload in intensive care unit of a tertiary care university hospital in relation to the patients' severity of illness: A prospective study. International Journal of Nursing Studies, 76, 100-105.

Lee, T.T., Mills, M.E. \& Lu, M.H. (2008). Impact of a nursing information system on practice patterns in taiwan. Computers Informatics Nursing, 26 (4), 207-214.

Munyisia, E.N., Yu, P. \& Hailey, D. (2011). How nursing staff spend their time on activities in a nursing home: An observational study. Journal of Advanced Nursing, 67 (9), 1908-1917.

Pelletier, D. \& Duffield, C. (2003). Work sampling: Valuable methodology to define nursing practice patterns. Nursing \& Health Sciences, 2003 (5), 31-38.

Qian, S., Yu, P., Zhang, Z., Hailey, D., Davy, P. \& Nelson, M. (2012). The work pattern of personal care workers in two australian nursing homes: A time-motion study. BMC Health Services Research, 12 (1), 305.

Schnelle, J.F., Ouslander, J.G. \& Simmons, S.F. (2006). Direct observations of nursing home care quality: Does care change when observed? J Am Med Dir Assoc, 7 (9), 541-544.

Sittig, D.F. (1993). Work sampling: A statistical approach to evaluation of the effects of computers on work patterns in health care. Methods of Information in Medicine, 32 (2), 167-174.

Urden, L.D. \& Roode, J.I. (1997). Work sampling. A decision-making tool for determining resources and work redesign. $J$ Nurs Adm 27 (9), 34-41.

Westbrook, J.I. \& Ampt, A. (2009). Design, application and testing of the work observation method by activity timing (wombat) to measure clinicians' patterns of work and communication. Int J Med Inform, 78 Suppl 1, S25-S33.

Williams, H., Harris, R. \& Turner-Stokes, L. (2009). Work sampling: A quantitative analysis of nursing activity in a neuro-rehabilitation setting. Journal of Advanced Nursing, 65 (10), 2097-2107.

Williamson Jr, W.J. \& Johnston, J. (1988). Understanding, evaluating and improving nursing productivity. Nurs Manage, 19 (5), 49-50, 52, 54. 
1 Table 1. Classification of nursing work activities.

\begin{tabular}{|c|c|}
\hline Categories & Activities \\
\hline \multirow[t]{16}{*}{ Direct care } & Allocating beds to patients \\
\hline & Measuring a patient's vital signs \\
\hline & Ward round (checking and assessing patients' condition) \\
\hline & Basic care (e.g. oral care, perineal care, pressure ulcer care) \\
\hline & Activities of daily living (e.g. toileting, dressing, turning a patient in bed) \\
\hline & $\begin{array}{l}\text { Preparing a patient for tests (e.g. transferring a patient from a bed to a } \\
\text { wheelchair or a movable bed, taking off metal things from a patient) }\end{array}$ \\
\hline & Collecting specimens (e.g. urine collection, blood collection) \\
\hline & Rehabilitation training for a patient \\
\hline & Distributing test results to patients \\
\hline & Adjusting drip rate \\
\hline & Administering oral medications \\
\hline & Intravenous infusion \\
\hline & Checking patients during intravenous infusion \\
\hline & Changing or withdrawing intravenous medication \\
\hline & Administering medications via nasogastric tube feeding \\
\hline & $\begin{array}{l}\text { Administering medications (excluding oral medication and intravenous } \\
\text { infusion) such as a nebulizer }\end{array}$ \\
\hline \multirow[t]{11}{*}{ Indirect care } & $\begin{array}{l}\text { Managing ward environment (e.g. putting intravenous stands, adjusting bed } \\
\text { height) }\end{array}$ \\
\hline & Sorting out cabinets for storing gauze, adhesive tape etc. \\
\hline & Disposal of clinical waste \\
\hline & Maintenance and use of medical equipment \\
\hline & Pasting barcodes to containers for specimen collection \\
\hline & Counting and replenishing supplies and medications \\
\hline & $\begin{array}{l}\text { Checking medications including both long-term and short-term oral } \\
\text { medications and intravenous medications }\end{array}$ \\
\hline & $\begin{array}{l}\text { Pasting labels to a patient's medications and putting the medications in the } \\
\text { person's compartment }\end{array}$ \\
\hline & $\begin{array}{l}\text { Re-checking information about a patient and his or her medications (this } \\
\text { activity is done by a nurse different from the nurse who prepares } \\
\text { medications) }\end{array}$ \\
\hline & Preparing medications according to prescriptions \\
\hline & $\begin{array}{l}\text { Preparing equipment for intravenous infusion (e.g. putting prepared } \\
\text { medications, cotton swab, adhesive tape, infusion set on a plate in the } \\
\text { medication trolley) }\end{array}$ \\
\hline \multirow[t]{4}{*}{ Infection control } & Putting on personal protective equipment \\
\hline & Taking off personal protective equipment \\
\hline & Washing hand with water \\
\hline & Washing hand with hand sanitizer \\
\hline
\end{tabular}




\begin{tabular}{|c|c|}
\hline \multirow[t]{24}{*}{ Documentation } & Filling out an infusion card \\
\hline & Filling out a paper-based admission form et al. \\
\hline & Reading information on a desktop computer \\
\hline & $\begin{array}{l}\text { Batch recording and reviewing the vital signs of patients on desktop } \\
\text { computers }\end{array}$ \\
\hline & Entering admission data on a desktop computer \\
\hline & Recording nursing care on a computer \\
\hline & Reviewing nursing records on a computer \\
\hline & Recording information about patients using a piece of paper \\
\hline & Reviewing and entering prescriptions on a computer \\
\hline & Printing paper records (e.g. infusion cards and barcodes) \\
\hline & Sorting paper records \\
\hline & Checking paper-based prescriptions \\
\hline & $\begin{array}{l}\text { Checking information on paper-based records against electronic medical } \\
\text { orders of the week with another one or two nurses }\end{array}$ \\
\hline & Sorting test results and consultation sheets \\
\hline & $\begin{array}{l}\text { Preparing discharge advice of a doctor (e.g. reviewing handwritten } \\
\text { information from a doctor) }\end{array}$ \\
\hline & Filling out and checking discharge records on a desktop computer \\
\hline & Printing discharge records \\
\hline & Filling out paper-based discharge registers \\
\hline & Filling out and sorting paper records of discharged patients \\
\hline & Entering fees on a desktop computer \\
\hline & Filling out an application form for new supplies on a desktop computer \\
\hline & Registering paper-based inventory \\
\hline & Scanning barcodes and sending specimens for tests \\
\hline & Sorting infusion cards after intravenous infusion \\
\hline Staff break & $\begin{array}{l}\text { Personal errands (off unit chores; meal break; making personal telephone } \\
\text { call). }\end{array}$ \\
\hline Transit & Standing or walking in the corridor between activities \\
\hline \multirow[t]{9}{*}{ Verbal communication } & Training student nurses \\
\hline & Seeking help from another nurse \\
\hline & Assisting another nurse with his or her work \\
\hline & Participating in on-job training \\
\hline & $\begin{array}{l}\text { Communicating with others about a patient information (e.g. nursing } \\
\text { assistants transporting specimens) }\end{array}$ \\
\hline & Communicating with other nurses about a patient information \\
\hline & Communicating with doctors about a patient information \\
\hline & Communicating with patients and their family members \\
\hline & Receiving or making a phone call \\
\hline Others & Other tasks not included \\
\hline
\end{tabular}


Table 2. Comparison of hospital RNs' activities and time expenditure.

\begin{tabular}{|c|c|c|c|c|c|c|c|c|}
\hline Study & Our study & $\begin{array}{l}\text { (Antinaho et al., } \\
\text { 2014) }\end{array}$ & $\begin{array}{l}\text { (Abbey et al., } \\
\text { 2012) }\end{array}$ & (Williams et al., 2009) & $\begin{array}{l}\text { (Chaboyer et al., } \\
\text { 2008) }\end{array}$ & $\begin{array}{l}\text { (Hendrich et al., } \\
\text { 2008) }\end{array}$ & $\begin{array}{l}\text { (Lee et al., } \\
2008)\end{array}$ & $\begin{array}{l}\text { (Capuano et } \\
\text { al., 2004) }\end{array}$ \\
\hline Country & China & Finland & Australia & UK & Australia & US & China & US \\
\hline Setting & $\begin{array}{l}\text { Neurology } \\
\text { Department }\end{array}$ & $\begin{array}{l}\text { Internal medicine } \\
\text { units; surgical units; } \\
\text { psychiatric units }\end{array}$ & $\begin{array}{l}\text { Intensive care } \\
\text { unit }\end{array}$ & $\begin{array}{l}\text { Neurological } \\
\text { rehabilitation unit }\end{array}$ & Medical wards & $\begin{array}{l}\text { Medical surgical } \\
\text { units }\end{array}$ & $\begin{array}{l}\text { General } \\
\text { surgical } \\
\text { units }\end{array}$ & $\begin{array}{l}\text { Neuroscience } \\
\text { medical } \\
\text { surgical unit }\end{array}$ \\
\hline $\begin{array}{l}\text { NO. of observed } \\
\text { activities }\end{array}$ & 67 & 39 & 25 & 23 & 25 & 14 & 83 & 17 \\
\hline $\begin{array}{l}\text { Observation } \\
\text { method }\end{array}$ & time-motion & self-report & time-motion & work sampling & work sampling & $\begin{array}{l}\text { self-report } \\
\text { time-motion }\end{array}$ & \begin{tabular}{|l} 
work \\
sampling
\end{tabular} & $\begin{array}{l}\text { work } \\
\text { sampling }\end{array}$ \\
\hline Direct care & $14 \%$ & $\begin{array}{l}38 \% \text { (incl.10\% } \\
\text { communication) }\end{array}$ & $40.5 \%$ & $\begin{array}{l}\text { 37\% (incl.3.4\% } \\
\text { communication) }\end{array}$ & $\begin{array}{l}\text { 18-34.8\% } \\
\text { (incl. 4-5.31\% } \\
\text { communication) }\end{array}$ & \multirow{2}{*}{$\begin{array}{l}50.2 \% \text { Nursing } \\
\text { practice }\end{array}$} & $20 \%$ & $44 \%$ \\
\hline Indirect care & $14.6 \%$ & $\begin{array}{l}\text { 17\% (incl.2\% } \\
\text { communication) }\end{array}$ & $32.4 \%$ & $\begin{array}{l}\text { 37\% (incl.19.9\% } \\
\text { communication) }\end{array}$ & $\begin{array}{l}\text { 45.5-59.7\% } \\
\text { (incl.10.1-17.1\% } \\
\text { communication) }\end{array}$ & & $25 \%$ & $21.8 \%$ \\
\hline Documentation & $28.3 \%$ & $16 \%$ & - & - & - & $27.5 \%$ & $30 \%$ & $13.2 \%$ \\
\hline $\begin{array}{l}\text { Other categories } \\
\text { specific to a study }\end{array}$ & $\begin{array}{l}-3.6 \% \text { infection } \\
\text { control } \\
-8.2 \% \text { transit } \\
-28.5 \% \\
\text { communication } \\
\text { (8.8\% concurrently } \\
\text { spent on doing } \\
\text { another activity) } \\
-8.8 \% \text { staff break } \\
-2.8 \% \text { others }\end{array}$ & $\begin{array}{l}\text {-5\% indirect work } \\
\text { (e.g. organising } \\
\text { outpatient care) } \\
-9 \% \text { unit-related (e.g. } \\
\text { in-service education) } \\
-7 \% \text { personal time } \\
-8 \% \text { miscellaneous } \\
\text { work (e.g. waiting, } \\
\text { cleaning) }\end{array}$ & $\begin{array}{l}-5 \% \\
\text { unit-related } \\
\text { (e.g. } \\
\text { in-service } \\
\text { education, } \\
\text { clerical, } \\
\text { meetings) } \\
\text {-21.9\% } \\
\text { personal time }\end{array}$ & $\begin{array}{l}\text {-10\% unit-related (e.g. } \\
\text { replenishing supplies, } \\
\text { unit meetings) } \\
-16 \% \text { personal time } \\
\text { (e.g. education, } \\
\text { training, continuous } \\
\text { professional } \\
\text { development, meal } \\
\text { breaks) }\end{array}$ & $\begin{array}{l}-5.6-10.1 \% \\
\text { unit-related } \\
-12.1-13.7 \% \\
\text { personal time }\end{array}$ & $\begin{array}{l}-2.8 \% \text { unit-related } \\
-12.6 \% \text { non-clinical } \\
\text { (e.g. personal, } \\
\text { patient/family care) } \\
-6.6 \% \text { waste } \\
\text { (hunting or } \\
\text { gathering activities) }\end{array}$ & \begin{tabular}{|l}
$-9 \%$ \\
unit-related \\
$-15 \%$ \\
personal \\
time
\end{tabular} & $\begin{array}{l}-6.9 \% \\
\text { unit-related } \\
-13.8 \% \\
\text { personal time }\end{array}$ \\
\hline
\end{tabular}




\section{Figure legend}

Figure 1. Percentage of nursing time spent on each category of activities.

Figure 2. Activity time, frequency and duration of Charge RN and Support RN.

Figure 3. Distribution of durations of nursing activities.

Figure 4. Switches between activities. 


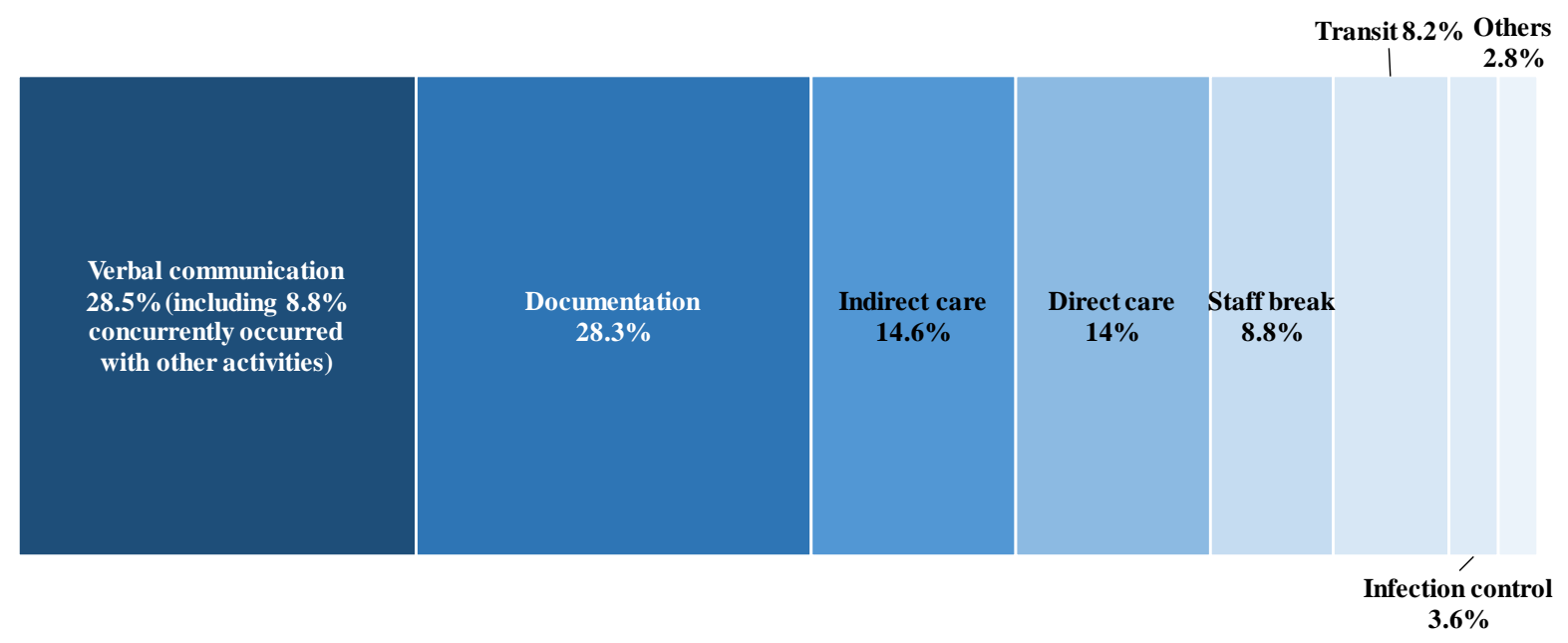

Figure 1. Percentage of nursing time spent on each category of activities. 

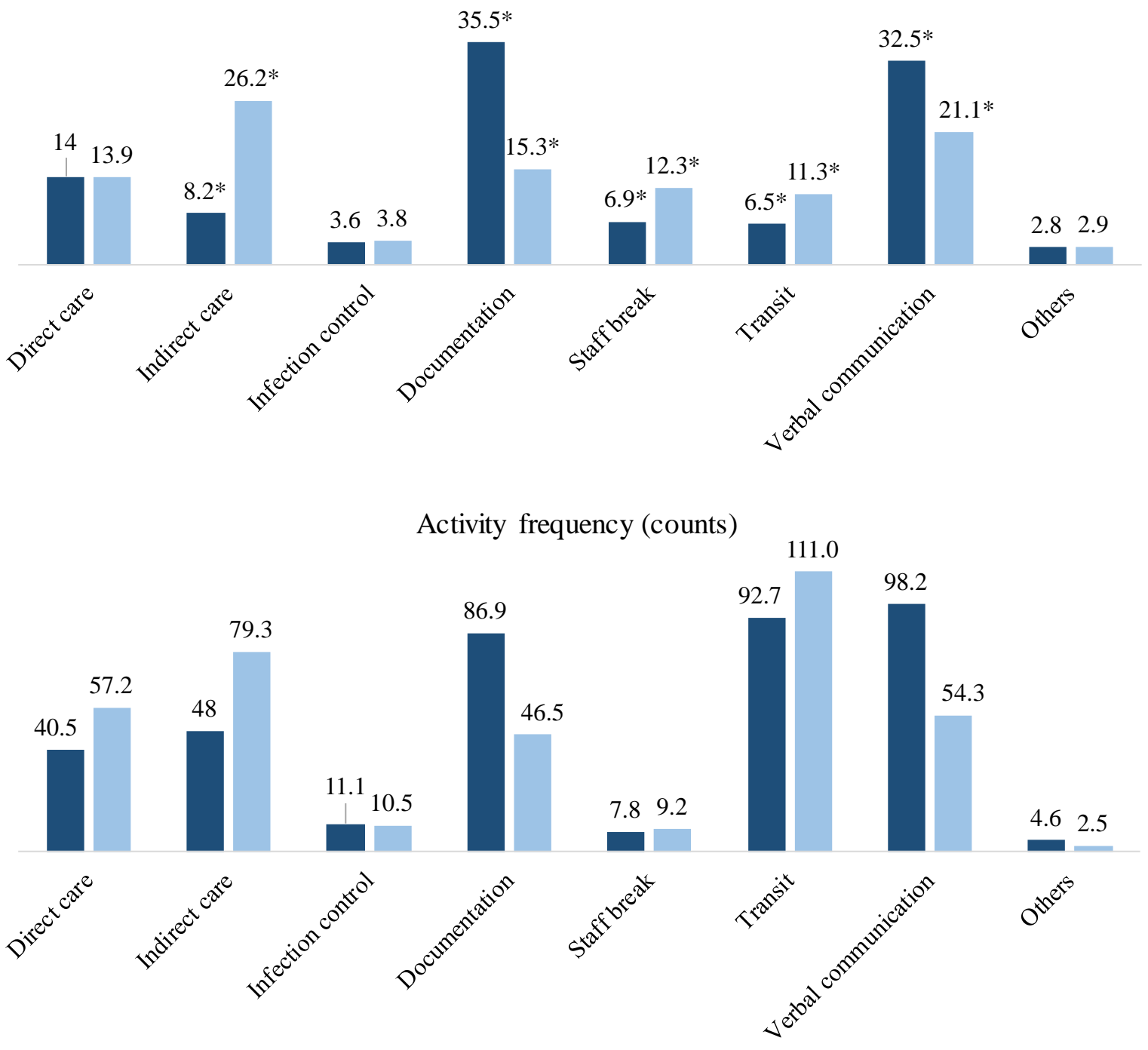

Activity duration (seconds)

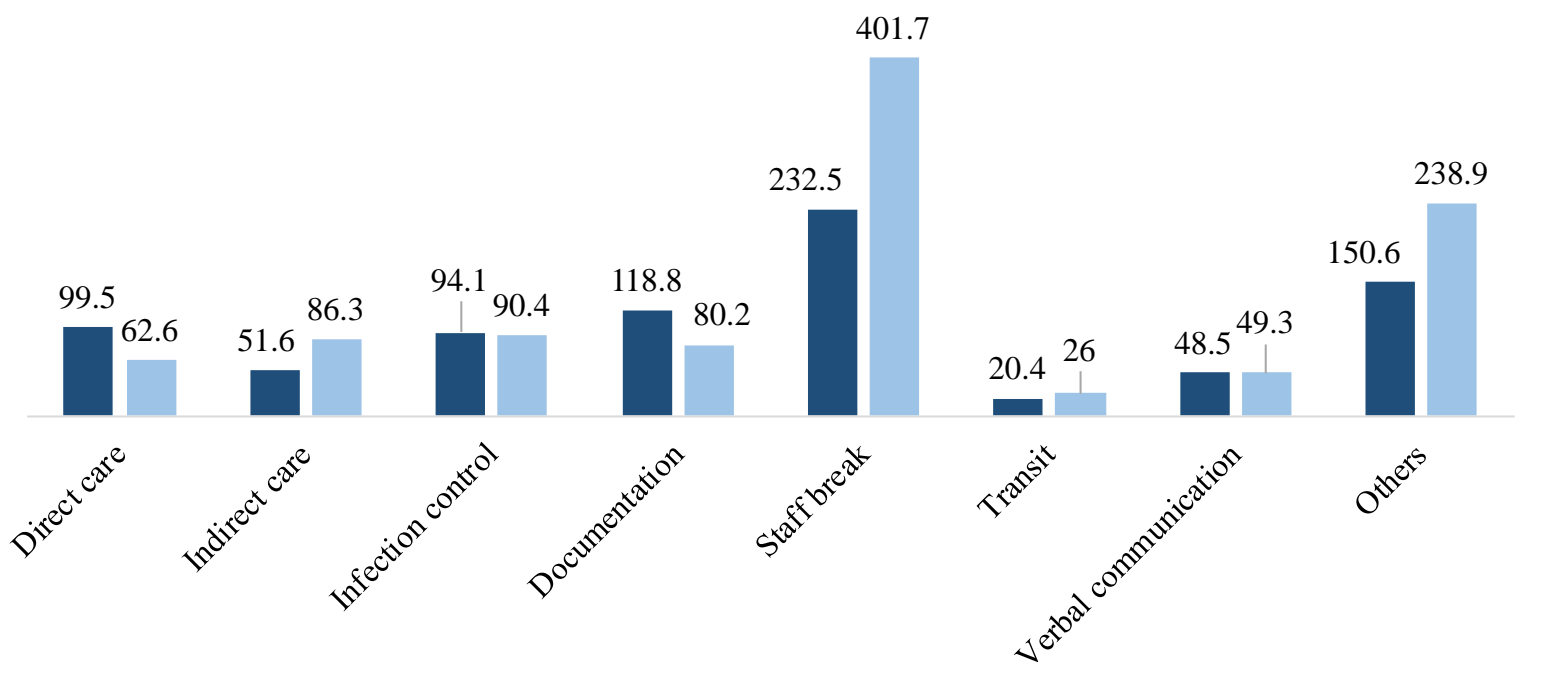

Figure 2. Activity time, frequency and duration of Charge RN and Support RN. 


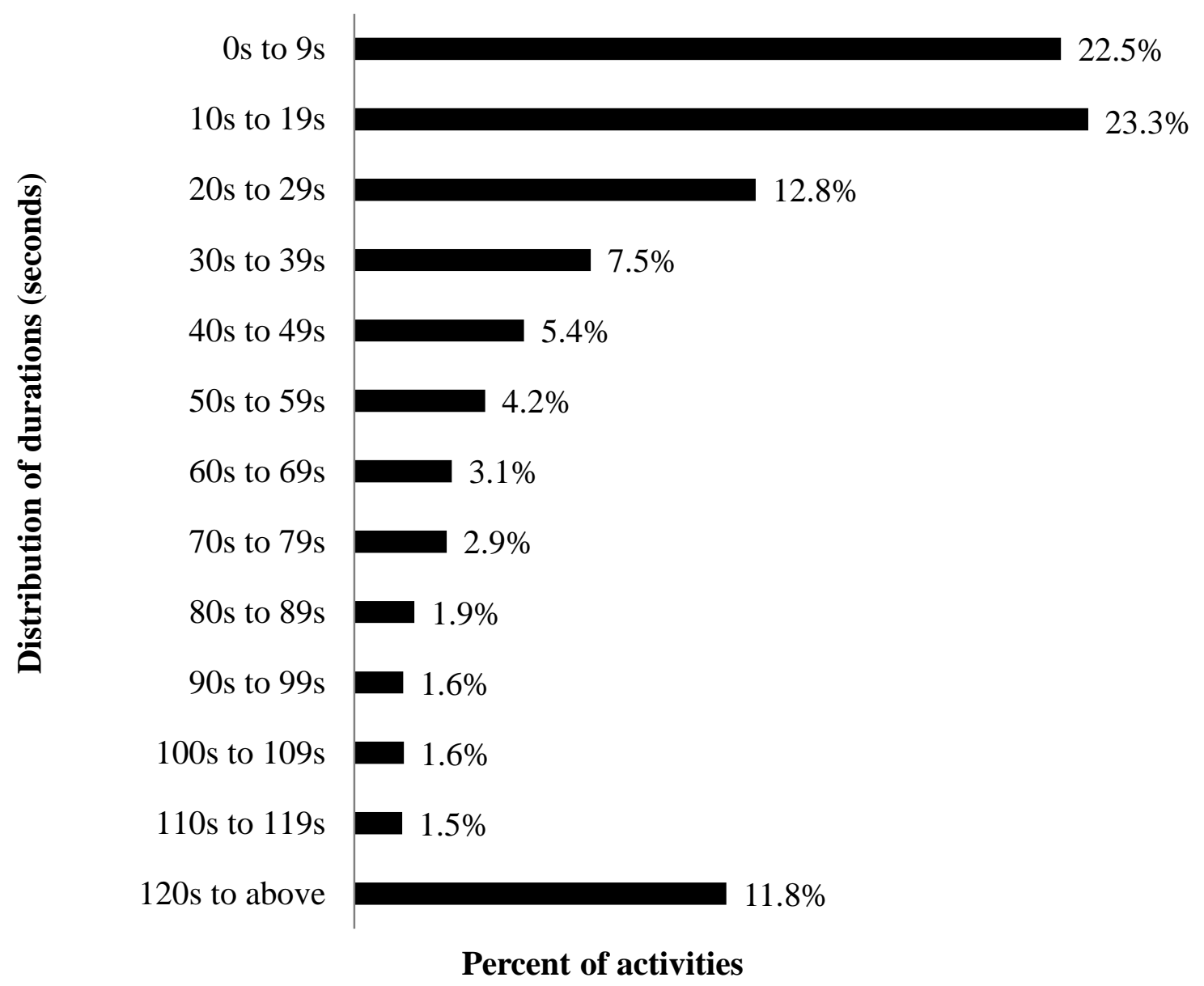

Figure 3. Distribution of durations of nursing activities. 


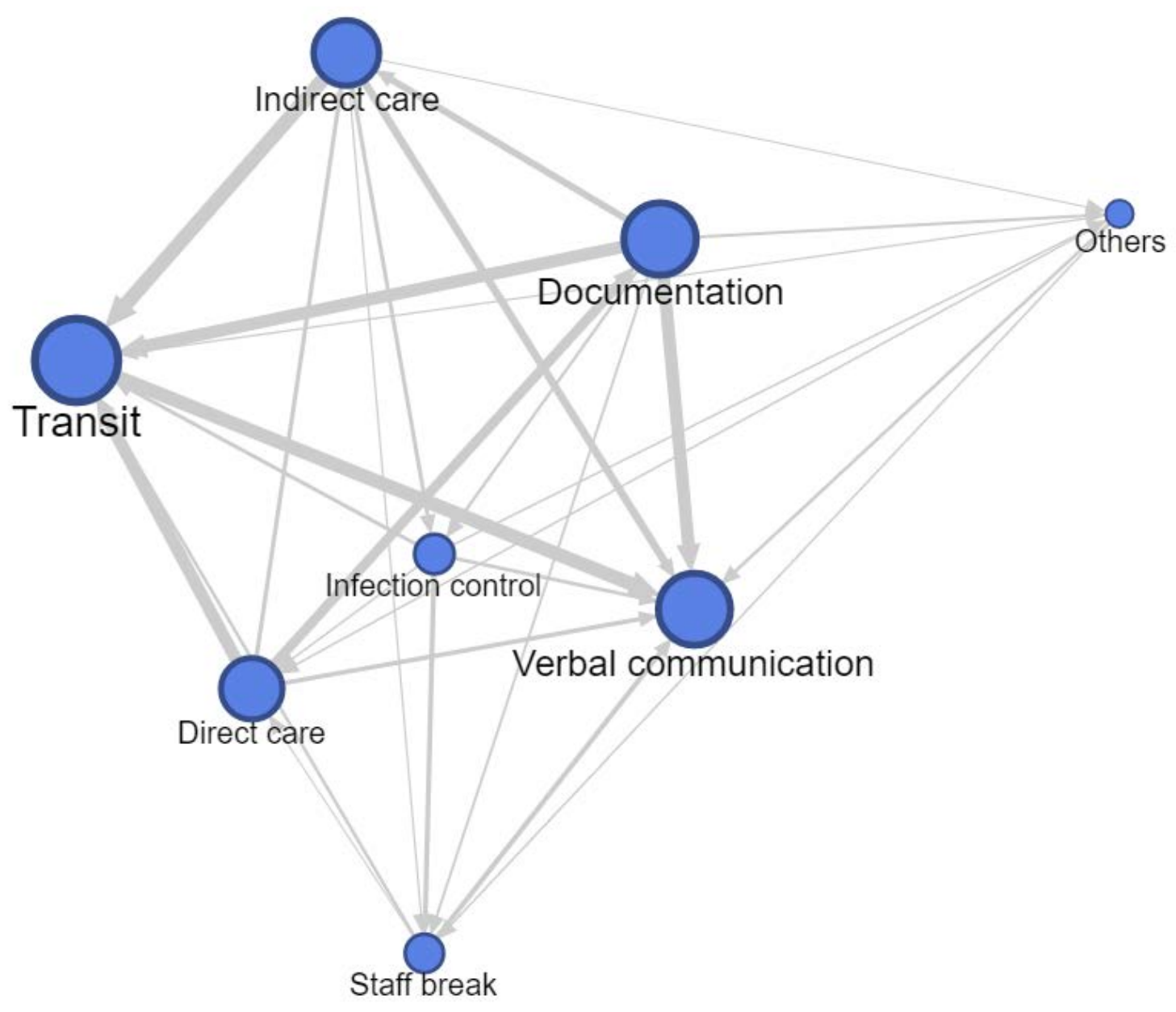

Figure 4. Switches between activities. 